\title{
Spending, Prices, and Employment in Early 1973
}

T

OTAL SPENDING in the economy rose at a sharply accelerated rate in the first quarter of this year, as both output and prices registered large increases. Following a pattern established early last year, output of goods and services has continued to increase substantially faster than the estimated longrun trend of productive capacity. The rapid growth of production in the first quarter had only a moderate effect, however, on reported rates of capacity atilization. The rate of unemployment in the labor force, for example, averaged 5 percent during the quarter, compared to 5.3 percent in the fourth quarter of 1972 . Although the unemployment rate and the capacity utilization index appear to indicate continued excess capacity in the economy, the rate of overall price increase rose in the first quarter, reflocting a substantial increase in the prices of consumer items within the quarter.

The combination of a stubbornly high rate of reported unemployment and an accelerated rate of inHation in the first quarter resulted in pressure from citizen and Congressional groups to reimpose some form of price controls in the economy. The apparent argument on which such recommendations have been based is that stimulus to aggregate demand is required to reduce the rate of unemployment, but the energence of inflationary pressures requires additional government action to restrict price increases.

The experience in the first quarter of this year must be interpreted with caution. The problem of growing inflationary pressures is real, but the severity is probably overstated by the recent price data. The price rise in the first quarter was partially a one-time increase resulting from a combination of random and non-recurring events. Similarly, the report that an average 4.5 million people cannot find jobs to which they aspire is distressing, but several factors caution against interpreting these data as indicative of substantial excess capacity in the economy.

\section{WUOLNI THNDS}

\section{spending}

Total spending on all goods and services (Gross National Product) increased at an exceptionally brisk 14 percent ammual rate in the first quarter of 1973 , following a rapid 11 percent increase during the previous year. By comparison, spending increased 7.2 percent during the early stage of economic recovery in 1971 , and at an average annual rate of 7.5 percent from 1964 to 1971 , a period of relatively strong inflationary pressures. In the 1957 to 1964 period, when inflation was relatively mild, on average, total spending rose at a 5.3 percent average annual rate.

The accelerated growth of spending in the first quarter of this year reflected a sharp increase in expenditures for consumer items, especially automobiles (a 39.6 percent rate of increase over the fourth quarter) and food products ( 17.8 percent). Purchases of consumer items rose at a 16 percent annual rate in the 


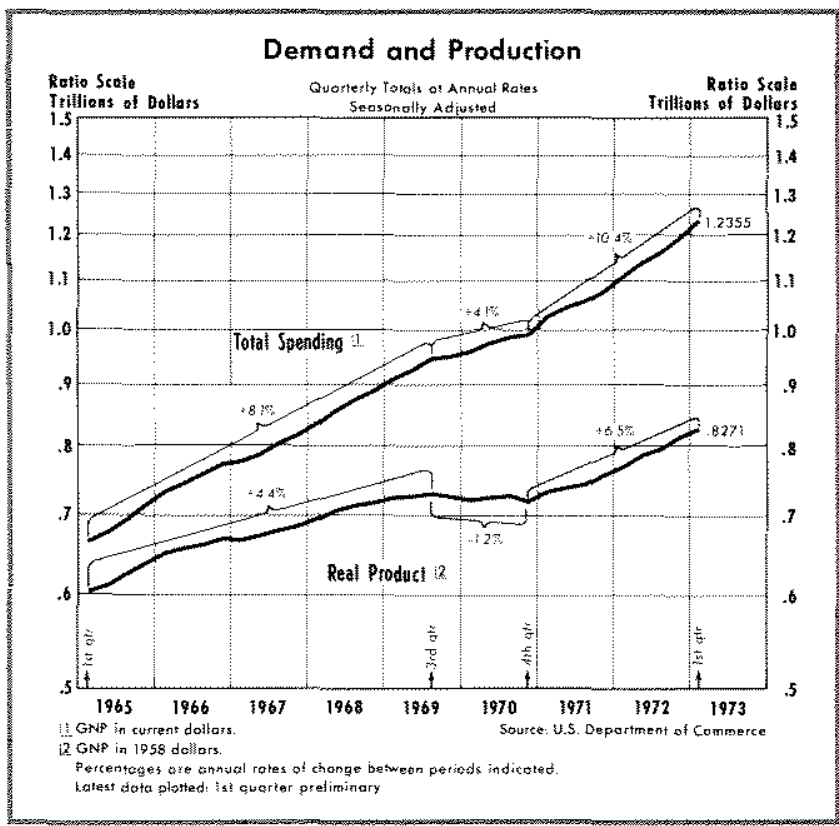

first quarter, reflecting a 35 percent rate of increase in expenditures for durables and a 13 percent rate of rise in nondurables. Over the previous year, total consumer spending had increased 9.6 percent.

Real product in the economy rose at a 7.9 percent annual rate in the first quarter, continuing the rapid rate of growth experienced in 1972 . Output rose 7.6 percent during 1972, and has increased at an average annual rate of 6.3 percent since the first quarter of 1971 , the first quarter of the current expansion. This rapid growth of production has resulted in a substantial gain in employment. Total civilian employment increased at a 3 percent rate from early in 1971 to March of this year.

\section{Prices}

Prices, as measured by the GNP price deflator, rose at an accelerated 6 percent annual rate in the first quarter of this year, compared to a 3 percent rise experienced during 1972 and a 3.6 percent increase in 1971. The recent accelerated rate of price increase reflected, in large part, both a sharp increase in consumer prices which began late last year and a pay increase for Federal employees. This latter item is treated in the national income accounts as an increase in the price of goods and services purchased by the Federal Government. Excluding this item from the price index yields a 5.6 rate of price increase in the quarter.

Consumer prices, as measured by the implicit price deflator for consumption expenditures, increased at a 5 percent annual rate in the first quarter, compared to

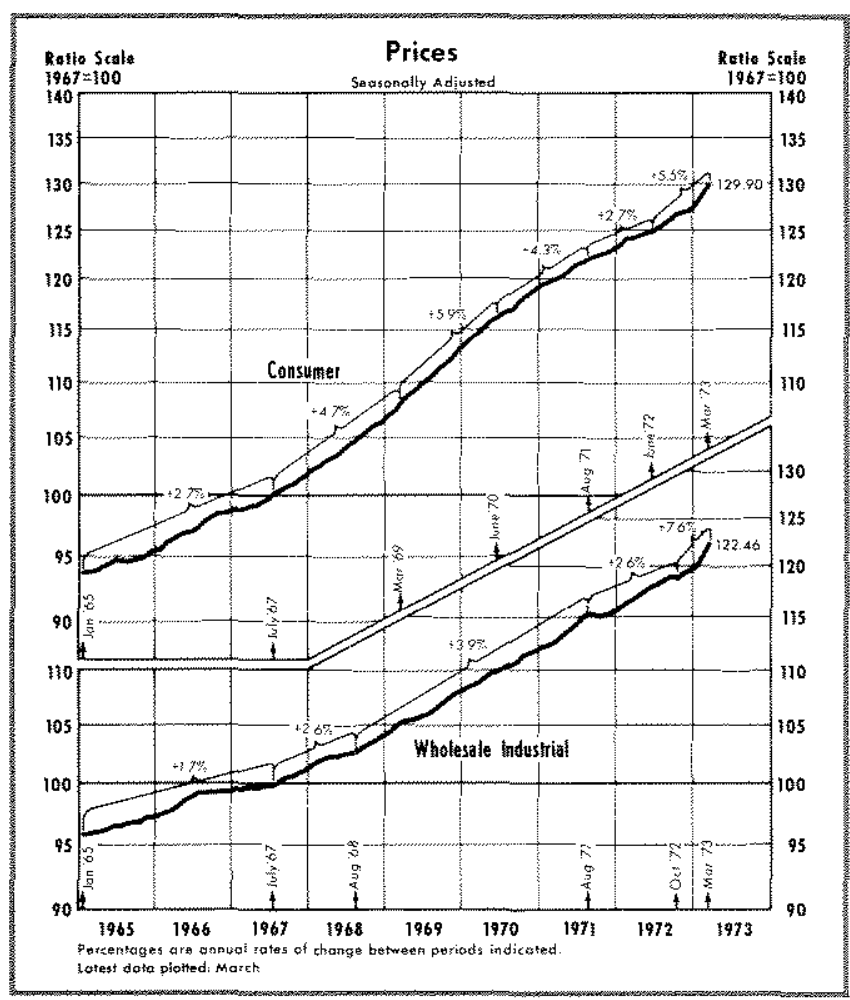

a 2.6 percent increase during 1972 . The rise in consumer prices, in turn, was largely reflective of increases in food prices. The food component of the consumer price index increased at a 21.6 percent annual rate from November to $\mathrm{March}$, compared to a 5.4 percent rise over the prior twelve months.

Some perspective on recent price developments is appropriate at this time. Inflation in this country reached a peak rate in late 1969 -early 1970 , with average prices rising at about a 6 percent annual rate. During most of 1970 , and until the "freeze" in August 1971, the rate of price increase generally declined. On average, since the control program began in August 1971 price increase have been more than 3 percent per year, despite three months of little change during the freeze. The accompanying table presents several measures of price developments by years.

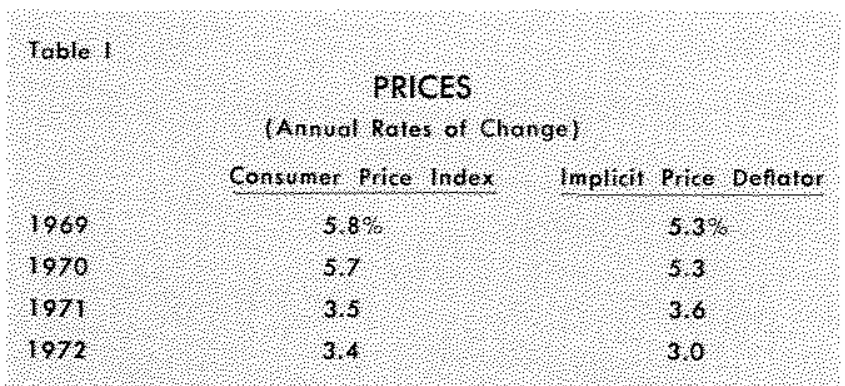

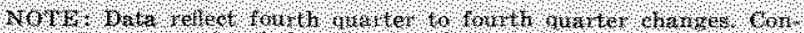

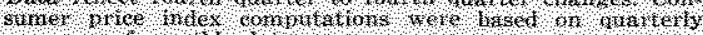

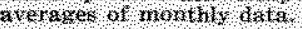




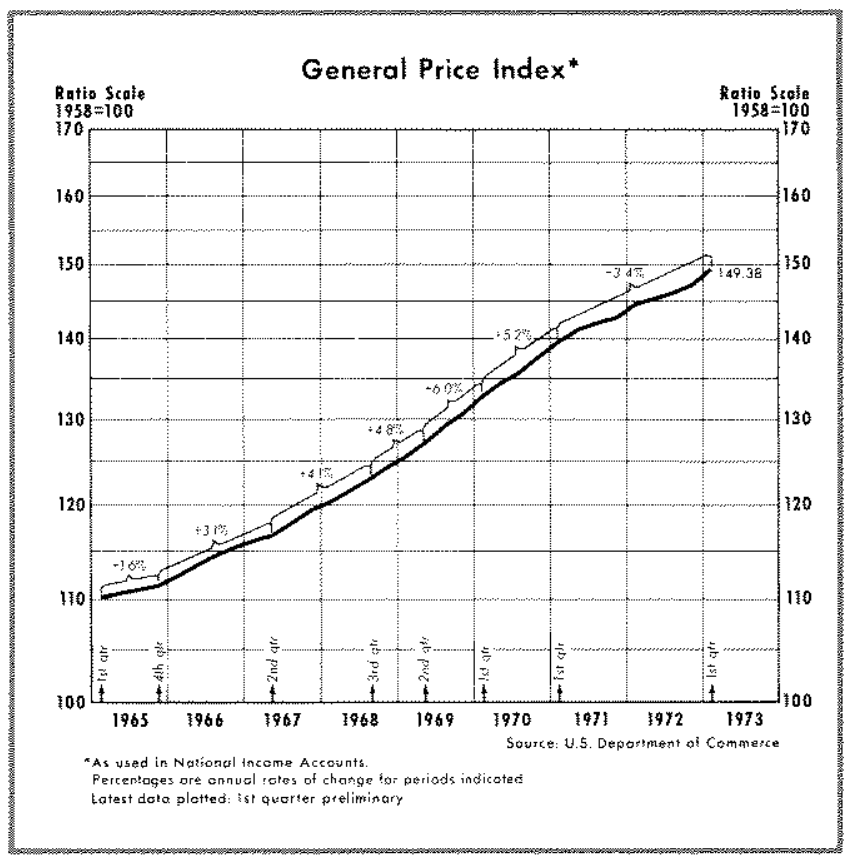

The increase of prices began to accelerate late last year. For example, from October to March this year, wholesale prices of farm products and processed foods and feeds increased at an exceptionally rapid 51 percent annual rate. To a significant extent, this jump was related to an unusual supply situation, and may be partially reversed at a later time. ${ }^{1}$ It also may be a reflection of an excessive total demand that price controls on other goods in 1972 diverted to food products.

In the first eight months of last year, consumer prices rose at a 3.2 percent annual rate. From August to December, these prices rose at a 3.8 percent rate. From December 1972 to March 1973 this year consumer prices rose at an even faster 8.8 percent rate. The most recent jump probably will not be sustained, however, since it reflects both an unusual agricultural situation and some catch-up price increases following the termination of Phase II of the price-wage control program.

\section{Ismploymerst}

Employment has been rising rapidly in response to the recent increases in demand for goods and services. From the end of 1971 until March 1973, total employment rose at a 3.8 percent annual rate. Population of working force age is estimated to have risen at about a 2 percent rate in the same period. In 1971 employment rose 2.1 percent, and the trend growth since 1952 has been at a 1.5 percent rate.

1See "Food and Agriculture in 1973", pp. 11-16 of this Review.

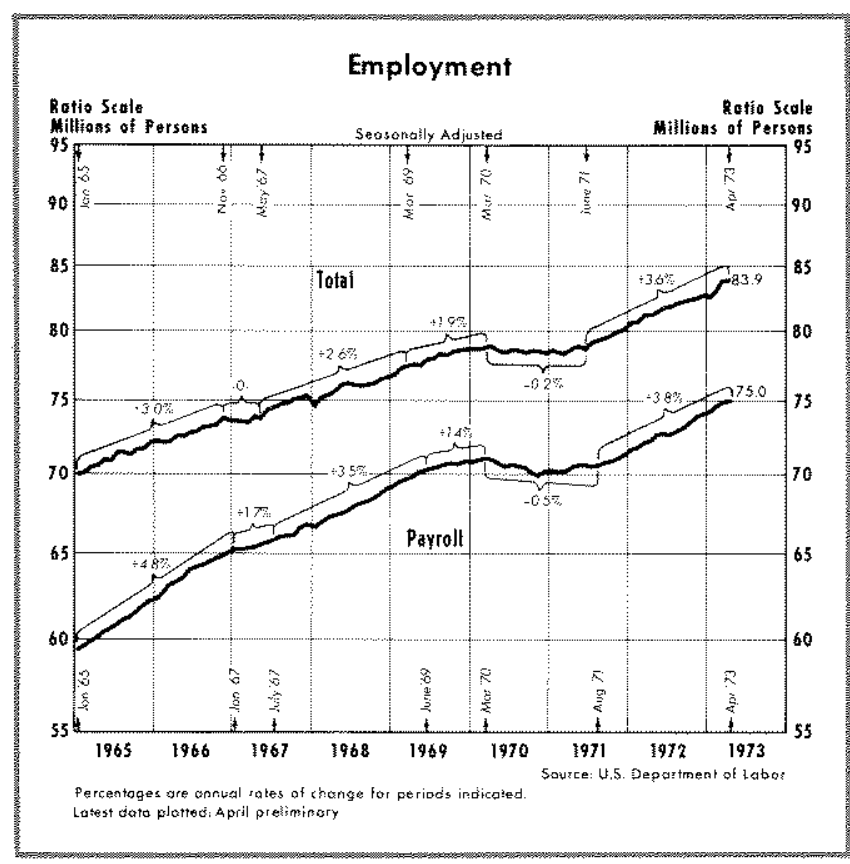

Although employment is now at a record level and rising at a rapid pace, there remains a significant number of people who report that they are seeking but are unable to find jobs. In recent months unemployment has been averaging about 5 percent of the labor force, down from the 6 percent level of 1971 and early 1972 , but substantially higher than the 4 percent or less that was observed in the late $1960 \mathrm{~s}$.

Given the current state of the arts, widespread disagreement would be expected as to the minimum sustainable level of unemployment which is consistent with relatively stable prices. For that matter, any such minimum is likely to change over time as the composition of the labor force, as the pattern of production, or the structural obstacles to employment change.

In only six of the fifteen years since 1957 did unemployment average less than 5.2 percent; these were the years 1965 through 1970. During this six-year span, unemployment averaged about 4 percent. In this period the increase in consumer prices accelerated from 1.2 percent in 1964 to 5.5 percent in 1970 . In another six of the years since 1957, unemployment was between 5.2 and 5.7 percent of the labor force (1959, 1960, 1962, 1963, 1964, and 1972). On average, during these six years the rate of increase in consumer prices remained virtually unchanged. In the remain ing three years, 1958, 1961, and 1971, unemployment was 5.9 percent or higher, and in each case the rate of inflation declined.

The current level of unemployment probably reflects a normal turnover, as businesses adapt to 


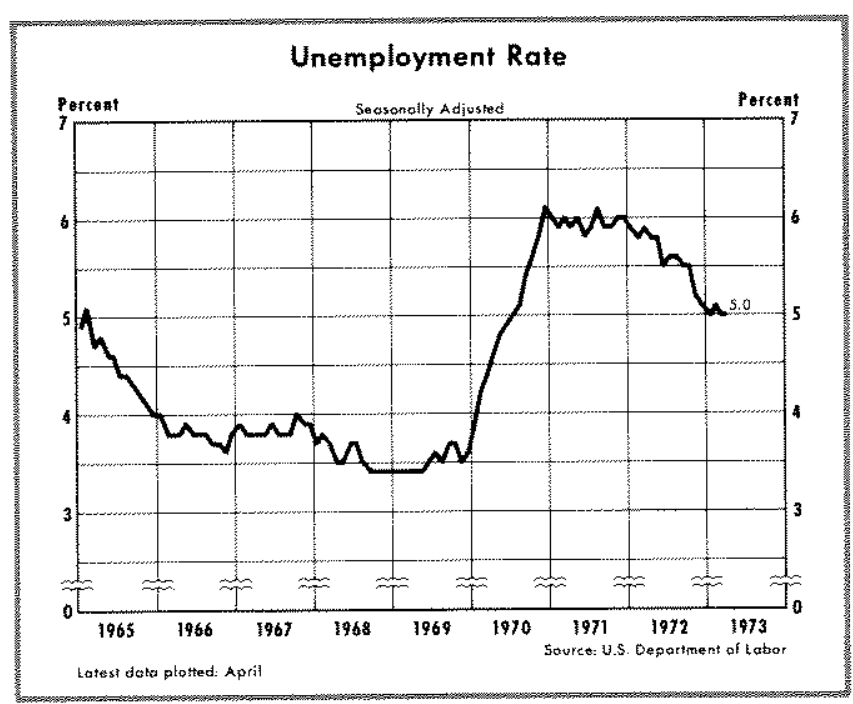

changing consumer demands, as new workers enter the labor market, and as others search for better job opportunities. Latest data indicate that 45 percent of those unemployed had been seeking work for four weeks or less and about 76 percent had been seeking work for less than three months. Also, at any one time there are some highly productive workers who are voluntarily unemployed while searching for better opportunities. This is probably explained by recognizing that one can usually engage in more intensive search for a job when not burdened by current employment responsibilities. In addition, search time has probably been extended by unemployment benefits ${ }^{2}$ and, for many, by the fact that other members in the household are working.

Demographic changes in the labor force seem to have been operating in recent years in such a way as to raise the minimum attainable level of unemployment. Since 1965 participation of women ( 16 years of age and older) in the labor force has risen from 39 percent to about 44 percent, while participation of men of the same ages has declined from about 82 percent to 79 percent. Since unemployment among women usually has been about 1.7 percentage points higher than for men since 1965, this shift in composition of the labor force probably has tended to raise the minimum level of unemployment attainable without intensifying inflation. Also, since 1965, the proportion of teenagers in the labor force, where unemploy-

\footnotetext{
2In a recent United States Department of Agricilture publication, it was noted that "A Tennessee father who is eligible for food stamps and the unemployment insurance maximum gain only $\$ 4$ a week by taking a part-tine job paying $\$ 75$ a week. In New Jersey the job must pay over $\$ 100$ a week before a similar man receiving memployment benefits and food stamps gains anything at all by working," [Alair A. Townsend, "National Issues in Welfare Reform," Outlook 73 , U.S.D.A.].
}

ment rates are also relatively high, has been growing substantially.

This shift in the structure of the labor force reflects, in part, the short-run effect of expectations of increased prices on the supply of labor. Families committed to a stream of payments, such as for prior purchases of durables, or families which have become accustomed to a given stream of income, would be expected to attempt to maintain their real income through wage increases or more intensive employment. The latter is achieved by moonlighting and having additional members of the family holding jobs.

\section{THE IMILICATIONS FOR PUTURE ACTIVITY}

The general pattern of economic activity in 1971 and 1972 was one of increasing production and employment, and deceleration in the rate of inflation. However, the rate of unemployment, while declining over the period, remained substantially higher than that experienced in the late 1960s. Similarly, the rate of inflation in late 1972 was just slightly more than half of that realized in 1969 , but still above the less than 2 percent average rate of inflation during the early to mid-1960s. This slow adjustment in both inflation and unemployment is evidence bearing on the strength of inflationary pressures which have been allowed to develop in the economy over the last half of the 1960s.

Inflation, in terms of a persistent rise in the average level of prices, is fundamentally a problem of excessive aggregate demand. In a growing economy, inflation results from a continuing stimulus to demand sufficient to outstrip the growth of production flowing from improved technology, increased productivity, and expansion of the stock of factors of production. This does not imply, however, that an immediate end to inflation can be secured by a restriction of aggregate demand. The longer an inflation is allowed to persist and the more severe it becomes, the more difficult it is to eliminate. The experience since 1970 reflects this unfortunate fact of life.

Economic activity is conducted on the best estimates by economic units of current and future market conditions. During a period of inflation, economic behavior becomes progressively more responsive to expectations of further inflation and less responsive to current conditions. Contract obligations are made, long lead-time projects are undertaken, and resources are allocated on the basis of expected future inflation. Once committed, economic units would be expected 
to resist the wealth losses which would result from an unexpected decline in the rate of inflation. Also, given the experience of the period since 1965, economic units probably now respond more quickly to protect themselves from rising prices.

If the growth of aggregate demand were to slow abruptly, then further increases in inflationary pres sures might be avoided, at least in the longer run. However, experience has shown that sharp cutbacks in demand have their initial effects on production and employment. Some reduction in the rate of growth of production is necessary, of course, as the economy approaches capacity. But an abrupt decline in the growth rate of demand and real output duning an adjustment period would not seem to be desirable.

If the reduction in the rate of increase of aggregate demand were gradual, the adverse effects on production might be avoided, or at least moderated greatly. But a gradual slowing which occurred only after production reached full capacity would probably be accompanied by a substantial build-up of inflationary pressures over the transition period. Later, then, the economy would be faced with the dilemma of either accepting the higher rate of inflation or enduring another period of sluggish real growth as expectations of inflation are reduced.

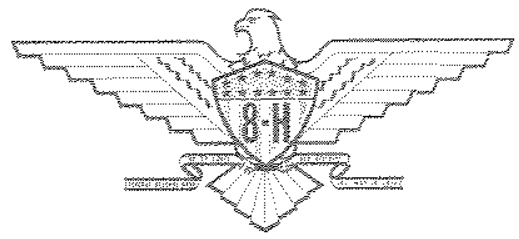

